AL-AZHAR UNIVERSITY BULLETIN OF THE FACULTY OF

LANGUAGES \& TRANSLATION
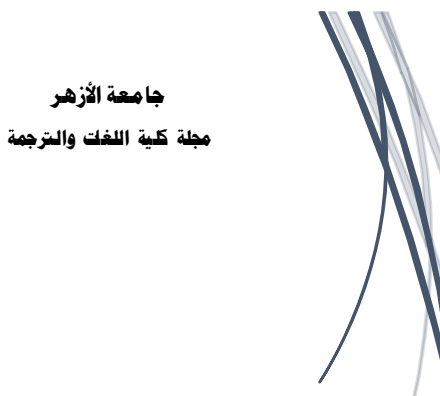

Impoverishment and Underspecification To Account For Syncretism Of Arabic Functional Morphemes

A Distributed-Morphological Account

Saleh Jarallah AIQahtani

Department of Linguistics and

Translation Studies

College of Languages and

Translation

King Saud University
Norah Al-Mufarrej

Department of Linguistics and

Translation Studies

College of Languages and

Translation

King Saud University 


\title{
Impoverishment And Underspecification To Account For Syncretism Of Arabic Functional Morphemes \\ A Distributed-Morphological Account
}

\section{Saleh Jarallah AlQahtani*, Norah Al-Mufarrej}

Department of Linguistics and Translation Studies, College of Languages and Translation, King Saud University, Riyadh, Kingdom of Saudi Arabia.

Corresponding Auther E-mail: alashry@ksu.edu.sa

\begin{abstract}
:
This paper aims to investigate three instances of syncretism in Arabic, namely number, gender, and Case marking. The study argues that syncretism of number values, attested in Verb-subject clauses and modified determiner phrases, can be accounted for by Vocabulary Item underspecification. Similarly, for gender syncretism, the study posits an underspecification rule that deletes the gender feature from the 2 nd and 3 rd dual pronouns, which results in genderless pronouns that can be used for masculine and feminine simultaneously. The last instance of syncretism is accusative/genitive Case marking. Assuming that Case is decomposed into primitive features, this paper proposes an impoverishment rule that deletes the oblique Case prior to Vocabulary Insertion. The proposed account in this paper relies on Distributed Morphology as a theoretical framework.
\end{abstract}

Keywords: Arabic, Case, Distributed Morphology, Impoverishment, Syncretism, Underspecification.

$$
\begin{aligned}
& \text { صالح جار الله القحطاني*، نورا المفرج } \\
& \text { قسم اللغويات ودراسات الترجمة، كلية اللغات والترجمة، جامعة الملك سعود، الرياض، المملكة العربية السعودية. } \\
& \text { البريد الإلكتروني للمؤلف الرئيسي: alashry@ksu.edu.sa }
\end{aligned}
$$

ههدف هذا البحث إلى دراسة الاختزال الصرفي المتمثل في الحالة العددية وحالة التذكير والتأنيث والحالة الإعرابية في اللغة العربية

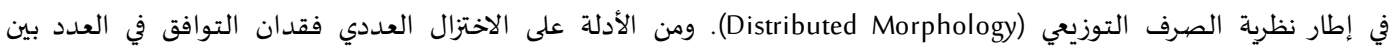
الفعل والفاعل كقولك (حضر الرجال/مفرد-جمع) وكذلك بين الاسم والصفة (الأفكار البناءة/جمع-مفرد). ولعلاج هذا الاختلاف

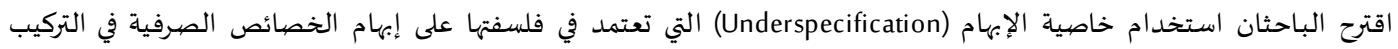

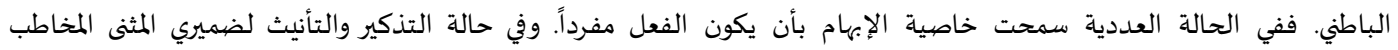
والغائب بأن يكونا مههي الجنس. واقترح الباحثان خاصية الاقتصار (Impoverishment) لتفسير ظاهرة الاختزال في الحالة الإعرابية والتي تعني استخدام وحدة صرفية واحدة للدلالة على حالتين إعرابيتين مختلفتين كاستخدام الياء والنون في حالتي النصب والجر في جمع المذكر السالم. 


\section{Introduction}

This paper intends to investigate syncretism of Case, number, and gender marking in Standard Arabic (SA). ${ }^{1}$ That is, Arabic exhibits syncretized phonological forms of the morphological exponents (inflectional markers), namely Case, number, and gender. Embick (2015) defines syncretism as the realization of two different functional morphemes by the same phonological form.

As for Arabic, the first instance of syncretism is reflected in Case marking. Case suffixes are phonologically realized by three variant forms, namely nominative, accusative, and genitive. However, there are structures where the accusative and genitive Case morphemes are realized by the same phonological form; see examples listed in (1) for illustrations of Case syncretism in feminine sound plural.

\section{(1) a. salam-t-u Sla Pal-banãt-i greet-I on the-girls-FEM-GEN 'I greeted the girls.' \\ b. Jahad-t-u ?al-banãt-i yaliabn see-I the-girls- $A C C$ playing 'I saw the girls playing.'}

The determiner phrase (DP) Pal-banãt- $i$ 'the girls' in examples (1a\&b) is suffixed with the same Case morpheme notwithstanding its different syntactic distribution in the two structures. That is to say, in example (1 1 a), ?al-banãt-i serves as the complement of a preposition and bears the genitive Case morpheme. By contrast, the syntactic distribution of the DP Pal-banatt-i in the structure (1 b) serves as the internal argument, the object, which underlyingly, thematically, takes the accusative Case, but in this situation, it is phonologically realized by the genitive Case form (i.e., the two examples represent Case syncretism). ${ }^{2}$

In the same vein, dual form for both types of gender shows instances of Case syncretism as illustrated by (2) for masculine and (ㅁ) for feminine.

\footnotetext{
${ }^{1}$ Throughout the paper, the term SA is used interchangeably with Arabic.

2 Abbreviations: (ABL)ative, (ACC)usative, (DAT)ive, (def) definite, (DL) dual, (DP) determiner phrase, (FEM)inine, (GEN)itive, (MSC) masculine, (NOM)inative, (PL)ural, (pl) plural feature, (SG) singular, (sig) singular feature, (SA) Standard Arabic, (SV) subject-verb order, (VI) Vocabulary Item, (VS) verb-subject order.
} 
(2) a. Jahad-t-u Pal-waladayn

see-I the-boy-MSC-ACC-DL

'I saw the two boys.'

(ACC Case)

b. salam-t-u Sla ?al-waladayn

greet-I on the-boy-MSC-GEN-DL

'I greeted the two boys.'

(GEN Case)

(3) a. Jahad-t-u Pal-bintayn

see-I the-girl-FEM-ACC-DL

'I saw the two girls.'

(ACC Case)

b. salam-t-u Sla ?al-bintayn

greet-I on the-girl-FEM-GEN-DL

'I greeted the two girls.'

(GEN Case)

Both accusative and genitive Cases are phonologically realized by the same morphological exponents in (2) and (ㅁ) as shown above.

Similarly, masculine sound plurals utilize the identical phonological realization to mark Case. The below examples in (4) show how accusative Case and genitive Case are represented by the same morphological exponent.

(4) a. Jahad-t-u Pal-muhandisẽn

see-I the-engineers- $M S C-A C C$

'I saw the engineers.'

b. salam-t-u Yla Pal-muhandisẽn

greet-I on the-engineers- $M S C-G E N$

'I greeted the engineers.'

Table (1) summarizes instances of Case syncretism introduced above.

$\begin{array}{cccc} & \text { Nominative } & \text { Accusative } & \text { Genitive } \\ \text { Dual } & / \tilde{a} / & / \mathrm{ay} / & / \mathrm{ay} / \\ \text { Masculine plural } & / \tilde{\mathrm{o}} / & / \mathrm{e} / & / \mathrm{e} / \\ \text { Feminine plural } & / \mathrm{u} / & / \mathrm{i} / & / \mathrm{i} /\end{array}$

Table 1: Case exponents for dual and plural forms in SA

With respect to number, Arabic tends to show full agreement in most structures (e.g., subject-verb, noun-adjective). However, there are cases where number agreement is lost between these elements, such as the number agreement mismatch between the noun and the adjective in DPs and between the verb and the subject in verb-subject (VS) structures, as shown by the following examples respectively: 
(5) a. Pal-dz̧ibãl-u Pan-na?ifãt-u

the-mountains- $N O M$ the-high- $P L-N O M$

'the high mountains'

b. Pal-dżibãl-u ?an-na?ifat-u

the-mountains- $N O M$ the-high- $S G-N O M$

'the high mountains'

(Full agreement in DP)

(Defective agreement in DP)

(6) a. Pal-Pawlãd-u Jareb-u Pal-Yașir-a

The-boys-NOM-MSC drank-PL-NOM-MSC the-juice-ACC

'The boys drank the juice.'

(Full agreement in SV)

b. Sareb-a Pal-?awlãd-u Pal-Yasir-a

drank- $S G-M S C$ the-boys- $M S C$ the-juice- $A C C$

'The boys drank the juice.'

(Defective agreement in VS)

Examples in $(\underline{5} a \& b)$ respectively show full and defective number agreement within the same DP. Similarly, example (ㅁa) shows full number agreement between the subject and the verb in subject-verb (SV) structures whereas example (6b) shows defective number agreement between the subject and the verb in VS structures.

The last instance of syncretism being investigated in this paper is gender marking syncretism. Arabic pronominal system tends to have subject pronouns inflected for masculine and feminine gender; consider (그-h) below. 
(7)

a. Panta ðakyyun

you-SG-MSC smart-NOM-SG-MSC

'You are smart.'

b. Panti ðakyyatun

you-SG-FEM smart-NOM-SG-FEM

'You are smart.'

c. Pantum ?ðkyã?

you-PL-MSC smart-NOM-PL-MSC

'You are smart.'

d. Pantunna ðakyyãt

you- $P L-F E M$ smart-NOM-PL-FEM

'You are smart.'

e. howa ðakyyaun

he- $S G-M S C$ smart-NOM-SG-MSC

'He is smart.'

f. hiya ðakyyatun

she-SG-FEM smart-NOM-SG-FEM

'She is smart.'

g. hum ?ðkyã?

they-PL-MSC smart-NOM-PL-MSC

'They are smart.'

h. hunna ðakyyãtun

they-PL-FEM smart-NOM-PL-FEM

'They are smart.'

Strikingly, dual pronouns seem to lack this distinction as illustrated by examples (ㅁa-d) below.

(8) a. Pantumã ðakyyatãn

you- $D L-M S C$ smart-NOM-DL-FEM

'You are smart.'

b. Pantumã ðakyyãn you- $D L-M S C$ Smart- $\mathrm{NOM}^{-} D L-M S C$

'they are smart'

c. humã ðakyyatãn

they-DL-MSC smart- $D L-F E M$

'They are smart.'

d. humã ðakyyãn

they- $D L-M S C$ smart- $D L-M S C$

'They are smart.' 
In the structures above, the dual masculine pronouns (?antuma and humã) represent both masculine and feminine gender. Nevertheless, the pronoun agrees with the attributive adjectives in number, but not in gender.

This paper aims to investigate syncretism in the previous contexts within the framework of Distributed Morphology (DM) advocated by Halle and Marantz (1993, 1994); Harley and Noyer (2000); Embick and Noyer (2007); Bobaljik (2017). Precisely, it implements DM tools such as Impoverishment and Underspecification to account for the types of syncretism introduced above.

This paper proceeds as follows: the second section introduces some previous studies that have investigated syncretism cross-linguistically; the third section discusses the theoretical assumptions related to the current study; the fourth section presents an account of the syncretism instances introduced above, and the fifth section concludes the paper.

\section{Previous analyses}

This section introduces the phenomenon of syncretism in the sense of DM. Also, it outlines some previous accounts that have been proposed to address different kinds of syncretism.

\section{Syncretism}

One of the key principles of DM, as put forth by Kramer and Winchester (2018), is the morphological operation of Vocabulary Insertion. The idea is that, the grammar supplies the morphosyntactic feature bundles with Vocabulary Items (VI) that match (partially or fully) the features in those bundles. Kramer and Winchester (2018) argue that syncretism occurs when fewer features in those bundles are realized by VIs. In a similar view, Harley (2008) defines syncretism as the situation in which different values of morphosyntactic features are realized by the same phonological exponent via the process of Vocabulary Insertion. She provides examples of syncretism instantiated by the English copula (be).

(9) a. I was studying.

b. She/ He was studying.

c. You were studying.

d. We were studying.

e. They were studying. 
Looking at (9), it is noticed that the first and third singular forms of the past tense of the English copula (be) show syncretism 'was', the second singular 'were' and the first/second/third plural 'were' as demonstrated by the examples above.

\subsection{Number agreement syncretism}

This section is dedicated to discussing number agreement asymmetry. The first subsection discusses number agreement cross-linguistically. The second subsection discusses number agreement asymmetry in VS structures and in Arabic DPs.

\section{Number agreement asymmetry cross-linguistically}

According to Badecker (2007), partial (defective) agreement is attested in the literature. He states that this type of agreement is obligatory and exhibited in clauses where the target verb or predicate precedes the subject. Badecker discusses constructions with conjoined subjects from Welsh; see the below examples.
a. Gwelais I a'm brawd ein hunain saw- $1 S G \mathrm{I}-1 S G$ and $\mathrm{I}_{-1 S G}$ brother- $1 P L$ self 'My brother and I saw ourselves.' saw-2SG I-2SG and I- $2 S G$ brother- $2 P L$ self 'You and your brother saw yourselves.'
b. Gwelaist ti a'th frawd eich hunain

Badecker (2007)

As the examples in $(\underline{10} \mathrm{a} \& \mathrm{~b})$ suggest, number and gender agreement targets only the first conjoined subject, which results in agreement mismatch between the verb and the second conjoined subject. Badecker (2007) states that partial agreement in Welsh is an instance of concord argument. He proposes an Optimality Theoretic account to explain this type of agreement.

\section{Number agreement asymmetry in SA}

Word order variation in Arabic affects number agreement depending on the position of the subject, whether it is preverbal or postverbal. According to (Aoun et al., 1994), agreement relations between a verb and a subject is affected by the type of word order (SV, VS), see the illustrative examples (11): 

(11) a. Pal-?awlãd-u nãm-u the-boys- $N O M$ slept- $3 M S C-P L$ 'The children slept.'
b. nãm-a ?al-?awlãd-u slept-3MSC-SG the-boys-NOM 'The boys slept.'

As illustrated by the examples above, when the subject precedes the verb (11a), $\varphi$ agreement features (i.e., gender, person and number) hold between the preverbal subject and the verb. By contrast, when the subject follows the verb (11b), agreement holds only in gender and person. To analyze the asymmetric agreement in VS, Benmamoun (1993) and Aoun et al. (1994) provide a preminimalist analysis. They argue that number agreement is manifested by a structural relation between a functional head and its specifier. In SV structure, the subject is in a spec-head configuration with the verb resulting in full agreement. However, in VS structure, the verb is not in a spec-head relation with the subject which results in losing number agreement.

Number agreement in Arabic is not only limited to subject-verb configurations; it also extends to DPs. In other words, agreement holds between modifiers and modified nouns in singular and dual forms; see examples (12a\&b) and (13a $a b)$.
a. Pas-syyaratu Pal-dzadidatu
the-car-NOM-SG the-new-NOM-SG 'the new car'
b. Pas-syyaratãn Pal-dzadidatãn the-cars- $N O M-D L$ the-new-NOM-DL 'the new cars'
c. Pas-syyarãtu Pal-dzadidatu the-cars- $N O M-P L$ the-new-NOM-SG 'the new cars' 
a. Pal-fikratu Pal-banna?atu

the-idea-NOM-SG the-constructive-NOM-SG

'the constructive idea'

b. Pal-fikratãn ?al-bana?atãn

the-ideas- $N O M-D L$ the-constructive- $N O M-D L$

'the constructive ideas'

c. Pal-Pfkãru Pal-banna?atu

the-ideas-NOM-PL the-constructive- $N O M-S G$

'the constructive ideas'

It is not always the case that full agreement holds between the modified nouns and their modifiers. Non-human plural nouns in Arabic trigger singular feminine agreement on the adjective within the DP as shown by examples $(\underline{12} \mathrm{c})$ and $(\underline{13 \mathrm{c}})$ above. There is a mismatch between the noun and the adjective. It can be noticed that non-human plural determiner phrases and singular determiner phrases are identically modified by singular adjectival phrases. Saeed (2019) argues that non-human plural DPs are inherently singular, and the plural marker of these DPs exhibits morphosyntactic information that does not affect the inherently imposed singular feature value.

\subsection{Gender marking syncretism}

This section is dedicated to discussing gender syncretism cross-linguistically and in SA. Precisely, the first subsection briefly discusses the instances of syncretism cross-linguistically; the second subsection discusses gender marking of Arabic dual pronouns.

\section{Syncretism of gender marking cross-linguistically}

Syncretism is a cross-linguistic phenomenon and robustly attested in different languages. Kramer (2016) investigates syncretism in Coptic. She states that Coptic does not show gender distinction in plural pronouns, plural determiners, and plural verbal agreement. To account for this type of syncretism, she considers that as a case of metasyncretism (i.e., a kind of syncretism which holds between multiple contexts). Metasyncretism can be analyzed in DM by the impoverishment operation that can affect multiple syntactic feature bundles simultaneously prior to Vocabulary Insertion. Kramer employs an impoverishment operation to remove any gender feature in any plural feature bundles in Coptic, resulting in gender being syncretized in those contexts. 


\section{Gender syncretism in SA}

Arabic pronouns are inflected for number (singular, dual, plural), person (1st, 2nd, 3rd) and gender (masculine, feminine). Although SA distinguishes gender in singular and plural personal pronouns, it does not show this distinction in the dual form as shown by examples (ㅁa-d) which are conveniently repeated below as (14).
(14)
a. Pantumã ðakyyatãn you- $D L-M S C$ smart- $D L-F E M$ 'You are smart.'
b. Pantumã ðakyyãn you- $D L-M S C$ smart- $D L-M S C$ 'They are smart.'
c. humã ðakyyatãn
they- $D L-M S C$ smart- $D L-F E M$
'They are smart.'
d. humã ðakyyãn
'They are smart.'
they- $D L-M S C$ smart- $D L-M S C$

It can be noticed that the grammatical masculine dual subject pronouns simultaneously express feminine and masculine gender, as shown by the examples above. Table (2) below summarizes dual personal subject pronouns in SA.

$\begin{array}{ccc}\text { Person } & \text { Gender } & \text { Pronoun } \\ 2 & \text { FEM } & \text { / } \text { 'antumã/ } \\ 3 & \text { MSC } & \\ 3 & \text { FEM } & \text { /humã/ } \\ & \text { MSC } & \end{array}$

Table 2: Dual subject pronouns in SA

Few theory-based studies have investigated the pronominal system in SA (Lumsden and Halefom, 2003; Albuhayri, 2013). Both studies give morphological and syntactic analyses of the derivation of pronouns in SA. Nonetheless, neither Lumsden and Halefom (2003) nor Albuhayri (2013) has provided an account of the gender syncretism of dual personal pronouns in $\mathrm{SA}$; one of the current paper's aims is to fill this gap. 


\subsection{Case syncretism}

There is a universal generalization that free word order languages tend to make use of Case marking (Butt et al., 2009). In other words, DPs that occupy subject positions are inflected for nominative Case whereas DPs that occupy object positions are inflected for accusative Case, and DPs that act as the complements of prepositions are inflected for genitive Case. However, this generalization may not be applicable in some contexts as far as the latter two are concerned. That is to say, different Case marking can be represented by the same phonological realizations. Baerman (2009) defines Case syncretism as the combination of multiple distinct Case values in a single form. The following subsections outline previous analyses of Case syncretism cross-linguistically and in SA.

\section{Case syncretism cross-linguistically}

Latin noun inflection system provides a clear example of syncretism. The ablative and dative Case suffixes are identical in the plural form. Latin nouns are organized into five classes. All classes are inflected for five Cases: nominative, accusative, ablative, genitive, and dative. In singular forms, all Cases are inflected by distinct suffixes, whereas in plural forms, ablative, and dative suffixes are identical in all five declensions; see Table ( $\underline{3}$ ) below.

$\begin{array}{cccccc}\text { Case } & \text { I } & \text { II } & \text { III } & \text { IV } & \text { V } \\ \text { pl.nom } & \text { mēns-ae } & \text { hort-Ī } & \text { cōnsul-ēs } & \text { frūct-ūs } & \text { rē-s } \\ \text { gen } & \text { mēns-ārum } & \text { hort-ōrum } & \text { cōnsul-um } & \text { frūct-uum } & \text { rē-rum } \\ \text { dat } & \text { mēns-Īs } & \text { hort̄̄s } & \text { cōnsul-ibus } & \text { frūct-ibus } & \text { rē-bus } \\ \text { acc } & \text { mēns-ās } & \text { hortōs } & \text { cōnsul-ēs } & \text { frūctūs } & \text { rē-s } \\ \text { ab1 } & \text { mēns-Īs } & \text { hortĪs } & \text { cōnsul-ibus } & \text { frūct-ibus } & \text { rē-bus }\end{array}$

Table 3: Declension of five Latin plural nouns (Embick, 2015, p. 151).

To analyze Latin Case syncretism, Embick (2015) uses the case feature decomposition proposed by Halle (1997) as illustrated in Table (4) below.

$\begin{array}{cccccc} & \text { Nom } & \text { Acc } & \text { Gen } & \text { Dat } & \text { Abl } \\ \text { oblique } & - & - & + & + & + \\ \text { structural } & + & + & + & + & - \\ \text { superior } & + & - & - & + & +\end{array}$

Table 4: Latin Case features (Embick, 2015, p. 152) 
Embick (2015) posits an impoverishment rule in (15) that deletes the only feature that distinguishes ablative and dative Cases (structural feature) from the feature bundle prior to Vocabulary Insertion.

$$
\text { (15) }[ \pm s t r] \rightarrow \varphi /\left[{ }_{-}+-+o b l,+s u p,+p l\right]
$$

This rule leads the ablative and dative plural Cases to end up with the same morpheme. VIs in (16) are used to derive the plural nouns in Latin:
a. $[+o b l,+$ sup,$+p l] \leftrightarrow$ is $\quad / \mathrm{I}, \mathrm{II} \ldots$
b. $[+o b l,+\sup ,+p l] \leftrightarrow$ (i)bus $\quad / I I I, I V, V \ldots$.

VIs in $(\underline{16} \mathrm{a} \& \mathrm{~b})$ are the results of the rule $(\underline{15})$ and are responsible for Case syncretism in Latin nouns. That is, the $[ \pm$ structural $]$ feature in the ablative and dative Cases are deleted by the rule (15), and consequently the two Cases become identical.

\section{Case syncretism in Arabic}

Al-Balushi (2011) has descriptively investigated the reasons behind the lack of an independent morphological Case for the accusative Case in duals and sound plurals. He argues that the accusative Case morphology has entered the SA nominal system late. Consequently, the non-singular nouns borrowed their accusative Case suffixes from the genitive paradigm. Al-Balushis study is merely a descriptive account that does not rely on any theoretical framework; consequently, his argument may not be suitable to address Case syncretism. The current paper addresses this issue theoretically in light of DM approach. The authors are not aware of any study that has investigated syncretism of functional morphemes in Arabic. This study contributes to the investigation of the syncretism phenomenon.

\section{Theoretical assumptions}

This section introduces the main assumptions of the theoretical framework adopted in this paper. The DM approach put forth by Halle and Marantz (1993, 1994), Harley and Noyer (2000), Embick and Noyer (2007) and Bobaljik (2017) is exploited in the current paper. DM is a theory that rejects the presence of a unified lexicon, and as the name suggests, morphology is 
distributed between syntax and phonological form (PF) ( 1993). DM argues that syntax feeds PF. Nevertheless, morphological operations take place in syntax and in PF; this is a key point in the theory. Syntax generates structures by combining morphosyntactic feature bundles that need phonological realizations. These feature bundles are exponed at PF via Vocabulary Insertion (Embick and Noyer, 2007). Mapping the bundles of features that occupy syntactic terminals to the appropriate phonological expressions in the PF is referred to as the Late Insertion hypothesis. This hypothesis is considered one of the basic tenets of DM (Harley and Noyer, 2000).

Another basic process in DM is underspecification. Embick (2015) defines it as the situation in which VIs refer to only a subset of the features available in the syntactic nodes that they apply to. According to Harley and Noyer (2000), underspecification means that phonological expressions do not need to be fully specified for the syntactic positions where they can be inserted.

One more pivotal morphological operation in DM employed in this paper is impoverishment proposed by Bonet (1991). Impoverishment rules target the components of morphemes prior to Spell Out. They operate over syntactic feature bundles and delete a certain feature from a bundle before they are exponed (Bonet, 1991; Harley, 2008). Impoverishment is used to account for syncretism when a distinction that is made in one part of the language morphology can be neutralized in another context (Embick, 2015).

\section{Question and Hypothesis}

\section{Question}

How can different syntactic features that have identical phonological representations (instances of syncretism) be accounted for?

\section{Hypothesis}

Within the framework of DM, the current study hypothesizes that impoverishment and underspecification rules can account for syncretism of Case, number and gender marking in SA. 


\section{The account}

The study argues that the DM tools, impoverishment and underspecification, can account for: a) number agreement syncretism in Arabic VS structures and DPs; b) gender marking syncretism of dual personal pronouns, and c) accusative and genitive Case syncretism in dual and sound plural nouns. This section proceeds as follows: the first subsection discusses number agreement syncretism in VS structures and DPs; the second subsection presents an analysis of gender syncretism, and the last subsection investigates Case syncretism.

\subsection{Number agreement syncretism}

\section{Number agreement syncretism in VP}

For number agreement syncretism in VS structures, the study argues that VI must be underspecified to account for syncretism of number feature in VS structures. Specifically, underspecification is assumed to account for syncretism found in examples $(\underline{17 b} \& \mathrm{c})$, which show defective agreement. The defective agreement is caused by the absence of the dual/plural number feature.

$$
\begin{aligned}
& \text { a. Jareb-a Pal-walad-u Pal-Sașir-a } \\
& \text { drank-SG-MSC the-boy-SG-MSC} \text { the-juice- } A C C \\
& \text { 'The boy drank the juice.' } \\
& \text { b. Jareb-a Pal-waladãni Pal-Yașir-a } \\
& \text { drank- } S G-M S C \text { the-boys- } D L-M S C \text { the-juice- } A C C \\
& \text { 'The boys drank the juice.' } \\
& \text { c. Jareb-a Pal-Pawlãd-u Pal-Yașir-a } \\
& \text { drank- }-S G-M S C \text { the-boys- } M S C \text { the-juice- } A C C \\
& \text { 'The boys drank the juice.' }
\end{aligned}
$$

Examining the above examples, it can be noticed that full agreement is established between the verb and the postverbal subject in (17a). By contrast, defective agreement is established between the verb and the postverbal subject in (17b\&c). The verb fareb- $a$ 'drank' is the locus of syncretism. The fully specified features of the VI for number functional morpheme before the application of underspecification are as follows: 
(18) 3rd person/singular [-1, -2, -pl] $\leftrightarrow$ ?al-walad-u

3rd person/dual $\quad[-1,-2,-$ pl $] \leftrightarrow$ ?al-waladãni

3rd person/plural $\quad[-1,-2,+\mathbf{p l}] \leftrightarrow$ ?al-?awlãd-u

It can be noticed that the person feature is encoded as $[-1,-2]$, which by default is interpreted as [+3] (3rd person). The reason behind the use of $[-1,-2]$ is to keep the feature classification in a binary system. Interestingly, this binary system can account for 1 st person $[+1,-2]$ and 2 nd person $[-1,+2]$ as well. Similarly, the number feature is encoded by [pl]. In the case of singular or dual number, the feature [-pl] is used, whereas the feature [+pl] indicates plurality. It is clear that all features in (18) are being equal except [+pl] feature; this feature must be underspecified - deleted. The underspecification of $[+\mathbf{p l}]$ results in the grammaticality of $(17 \mathrm{~b} \& \mathrm{c})$, despite the fact that there exists a mismatch in number agreement between the verb and the subjects.

\section{Number agreement in DP}

Number agreement holds between the modifier and the noun in singular and dual forms as shown by the examples listed below.

(19) a. Pas-syyaratu Pal-dzadidatu

the-car- $N O M-S G$ the-new-NOM-SG

'the new car'

b. Pas-syyaratãn ?al-dzadidatãn the-car- $N O M-D L$ the-new-NOM-DL 'the two new cars'

Interestingly, this agreement does not hold in plural forms as shown below.

(20) a. Pas-syyarãtu Pal-dzadidatu

the-cars-NOM-PL the-new-NOM-SG

'the new cars'

b. Pal-Pfkãru Pal-banna?atu

the-ideas-NOM-PL the-constructive- $N O M-S G$

'the constructive ideas'

To account for number agreement syncretism in (20), the study assumes that VI of plurality feature of the noun is underspecified in the context where the modified noun is non-human.

\section{Noun}

Singular $[-\mathrm{pl},+\mathrm{def},-$ human $]$

Plural [+pl, +def, -human $\quad[-\mathrm{pl},+\mathrm{def},-$ human $]$

Table 5: Number feature specification 
Looking at Table (5), it can be observed that there is an agreement concord of features between the nouns and the adjectives except the plurality feature [+pl] as illustrated above; however, if the modified plural noun is non-human, underspecification deletes the plurality feature $[+\mathbf{p l}]$ which in turn spells out as a singular feature.

\subsection{Gender syncretism}

Following Harley's (2008) definition of metasyncretism as a type of syncretism that holds between multiple contexts and holds for a particular set of features in any language, the paper argues that gender is metasyncretized in all dual personal pronouns in SA. That is to say, gender syncretism targets second as well as third dual personal pronouns. Focusing on the case on hand, syncretism of gender in 2nd and 3rd dual forms in Arabic, the authors assume that the underspecification rule is a useful tool to capture gender syncretism, which can apply to multiple contexts simultaneously. The VIs listed in (21) are the 2nd and 3rd personal dual pronouns in Arabic.

(21) 2nd person/dual $[-1,+2,-$ sig,-pl, \pm MSC $] \leftrightarrow$ ?antumã

3rd person/dual $[-1,-2,-$ sig,-pl, \pm MSC $] \leftrightarrow$ humã

The proposed underspecification rule in (22) targets the gender feature in the feature bundles of the dual pronoun leading to the loss of gender distinction of the dual personal pronouns.

$$
[ \pm \mathrm{MSC}] \rightarrow \varphi[\ldots,- \text {-sig, }-\mathrm{pl}]
$$

The underspecification rule $(\underline{22})$ dictates that in the context of dual pronoun, which is represented by the VIs [-sig,-pl], the gender feature is underspecified.

\subsection{Case syncretism}

Harley (2008) defines syncretism as different values of morphosyntactic features that are realized by the same phonological exponent via the process of Vocabulary Insertion. Accordingly, the morphosyntactic features that represent the accusative and genitive Cases are provided by the same phonological exponents. Departing from this point, it can be argued that accusative and genitive Cases of dual and sound plural are instances of metasyncretism. Being so, it is assumed that impoverishment can account for Case syncretism. For a convenient discussion, Table (1), reintroduced as ( $\underline{6})$ below, visualizes Case syncretism in dual and sound plural forms. 
Nominative

Accusative Genitive

$\begin{array}{llll}\text { Dual } & \text { /ã/ } & \text { /ay/ } & \text { /ay/ } \\ \text { Masculine plural } & / \tilde{o} / & \text { /ẽ/ } & \text { /ẽ/ } \\ \text { Feminine plural } & / \mathrm{u} / & \text { /i/ } & \text { /i/ }\end{array}$

Table 6: Case exponents for dual and plural

forms in SA

Excluding nominative Case, accusative and genitive Cases are represented by the same exponent, phonological realizer, respectively: dual form /ay/, masculine plural form /ẽ/ and /i/ for the feminine form.

To analyze Case syncretism, Case feature decomposition proposed by Halle (1997), illustrated in Table (7), is used to decompose the Arabic accusative and genitive Cases into primitive features.

$\begin{array}{llllll} & \text { Nom } & \text { Acc } & \text { Gen } & \text { Dat } & \text { Abl } \\ \text { oblique } & - & - & + & + & + \\ \text { structural } & + & + & + & + & - \\ \text { superior } & + & - & - & + & +\end{array}$

Table 7: Case features

The impoverishment rule (23) is posited to account for Case syncretism in SA:

$$
[ \pm \mathrm{obl}]-\rightarrow \varphi /\left[{ }_{[}+\text {str, }- \text { sup, }, \text { sg }\right]
$$

The impoverishment rule targets the primitive feature [oblique] that distinguishes accusative from genitive Case in non-singular environments and deletes it (i.e., it has zero value, $\varphi$ ). The process of deletion results in the identical phonological realization of the two Cases. This applies to all instances of Case syncretism illustrated in Table ( $\underline{6})$ prior to the Vocabulary Insertion process. 


\section{Conclusion}

In summary, this paper proposed a novel account of syncretism in Arabic. To be precise, it argued that syncretism of number agreement in VS structures and modified DPs is achieved by underspecifying the [+pl] feature bundled in VI. For gender syncretism, it proposed that the gender feature of the dual pronoun is underspecified, which results in genderless pronouns. Lastly, for the syncretism of accusative/genitive Case, the study assumed that Case must be first decomposed into primitive features; then the impoverishment rule deletes the oblique Case since it distinguishes accusative Case from genitive Case. The deletion results in a syncretized form which is phonologically realized by the same exponent.

\section{References}

Al-Balushi, R. (2011). The accusative case suffixes in Standard Arabic: Where from? International Journal of Arabic Linguistics 1:28-66.

Albuhayri, S. (2013). The pronominal system in Standard Arabic: Strong, clitic and affixal pronouns. Master's thesis, Arizona State University.

Aoun, J., Benmamoun, E., and Sportiche, D. (1994). Agreement, word order, and conjunction in some varieties of Arabic. Linguistic inquiry 195-220.

Badecker, W. (2007). A feature principle for partial agreement. Lingua 117:1541-1565.

Baerman, M. (2009). Case syncretism. Oxford University Press 219-243.

Benmamoun, E. (1993). Functional and inflectional morphology problems of projection, representation and derivation.

Bobaljik, J. (2017). Distributed morphology. In Oxford research encyclopedia of linguistics.

Bonet, E. (1991). Morphology after syntax: Pronominal clitics in Romance. MIT.

Butt, M. et al. (2009). Modern approaches to Case: an overview. The Oxford Handbook of Case, Oxford 27-43.

Embick, D. (2015). The morpheme: A theoretical introduction, volume 31. Walter deGruyter GmbH \& Co KG. 
Embick, D., and Noyer, R. (2007). Distributed morphology and the syntax/morphology interface. The Oxford handbook of linguistic interfaces 289324.

Halle, M. (1997). Distributed morphology: Impoverishment and fission. MIT Working Papers in Linguistics 30 425-449.

Halle, M. and Marantz, A. (1993). Distributed morphology and the pieces of inflection. The view from building 20: Essays in Linguistics in Honor of Sylvain Bromberger, ed. Kenneth Hale and Samuel Jay Keyser, 111-176. Cambridge, Massachusetts: MIT Press.

Halle, M. and Marantz, A. (1994). Some key features of distributed morphology. MIT working papers in linguistics 21:88.

Harley, H. (2008). When is a syncretism more than a syncretism? Impoverishment, meta-syncretism, and underspecification. Phi theory: Phifeatures across modules and interfaces 251-294.

Harley, H. and Noyer, R. (2000). State-of-the-article: Distributed morphology. Glot International 4.

Kramer, R. (2016). Syncretism in paradigm function morphology and distributed morphology. Morphological metatheory 95-120.

Kramer, R. and Winchester, L. (2018). Number and Gender Agreement in Saudi Arabic: Morphology vs. syntax1. Mayowa Akinlotan 39.

Lumsden, J. and Halefom, G. (2003). Verb conjugations and the strong pronoun declension in Standard Arabic. Amsterdam studies in the theory and history of linguistic science series 4 305-338.

Saeed, F. (2019). Verbal anti-agreement with non-human DPs. International Journal of English Linguistics, 9 (5), 362-376 